\title{
Dietary silicon intake in post-menopausal women
}

\author{
S. A. McNaughton ${ }^{1}$, C. Bolton-Smith ${ }^{1}$, G. D. Mishra ${ }^{1}$, R. Jugdaohsingh ${ }^{2}$ and J. J. Powell ${ }^{1,2 *}$ \\ ${ }^{1}$ MRC Human Nutrition Research, Elsie Widdowson Laboratory, Fulbourn Road, Cambridge CB1 9NL, UK \\ ${ }^{2}$ Gastrointestinal Laboratory, Rayne Institute, St Thomas's Hospital, London SE1 7EH, UK
}

(Received 15 December 2004 - Revised 6 June 2005 - Accepted 15 June 2005)

\begin{abstract}
Si has been suggested as an essential element, and may be important in optimal bone, skin and cardiovascular health. However, there are few estimates of dietary Si intakes in man, especially in a UK population. Following the development of a UK food composition database for Si, the aim of the present study was to investigate dietary intakes of Si amongst healthy women aged over 60 years and to identify important food sources of Si in their diet. Healthy, postmenopausal female subjects ( $>60$ years of age; $n$ 209) were recruited from the general population around Dundee, Scotland as part of an unrelated randomised controlled intervention study where dietary intake was assessed using a self-administered, semi-quantitative food-frequency questionnaire at five time-points over a 2-year period. Food composition data on the Si content of UK foods was used to determine the Si content of food items on the foodfrequency questionnaire. Mean Si intake was 18.6 (SD 4.6) mg and did not vary significantly across the 2 years of investigation. Cereals provided the greatest amount of Si in the diet (about $30 \%$ ), followed by fruit, beverages (hot, cold and alcoholic beverages combined) and vegetables; together these foods provided over $75 \%$ about Si intake. Si intakes in the UK appear consistent with those reported previously for elderly women in Western populations, but lower than those reported for younger women or for men.
\end{abstract}

Silicon: Dietary intake: Dietary patterns: Food-frequency questionnaire

Although Si has been of interest with respect to human health since the early 1900s it has only been suggested as an essential nutrient since the 1970s (Nielsen, 1999). Animal studies in chicks and rats have suggested that $\mathrm{Si}$ as orthosilicic acid $\left(\mathrm{Si}\left(\mathrm{OH}_{4}\right) \leftrightarrows \mathrm{Si}(\mathrm{OH})_{3} \mathrm{O}^{-}+\mathrm{H}^{+}\right)$may play an important role in skeletal and connective tissue formation (Carlisle, 1981), mainly due to its promotion of collagen synthesis, which may be due to its contribution to prolyl-hydroxylase activity as discussed by Reffitt et al. (2003). Analyses of the Framingham Offspring Cohort have shown that $\mathrm{Si}$ intake was positively associated with bone mineral density in men and pre-menopausal women, even after adjustment for confounding factors (Jugdaohsingh et al. 2004). Si has also been postulated as a protective factor in the development of atherosclerosis and it has been suggested that $\mathrm{Si}$ may play a role in maintaining the integrity and stability of arterial walls (Schwarz, 1977; Schwarz et al. 1977), again, presumably due to effects on collagen-like molecules of the vasculature. Finally, Si may interact with the metabolism of other minerals and, at least in lower organisms, a role for orthosilicic acid in preventing aluminium toxicity has been identified (Parry et al. 1998; Jugdaohsingh et al. 2000).

The Si content of foods varies depending on the food type, the processing of the food and the use of Si-containing food additives. Plant foods, particularly cereal-based products, contain high levels of $\mathrm{Si}$ (phytolithic silica) compared to animal foods, while refined products, such as refined cereals, contain less than unrefined products (Pennington, 1991). Si-containing food additives are used as anti-caking agents and are also used in the processing of certain beverages (Expert Group on Vitamins and Minerals, 2003); however the form of Si used in such additives is generally particulate and considered non-bioavailable (Jugdaohsingh et al. 2000). Drinking water and beverages also represent good sources of Si (Perez-Granados \& Vaquero, 2002; Sripanyakorn et al. 2004).

There are few published estimates of the dietary intake of $\mathrm{Si}$ in man, especially in the UK. It is commonly considered that human intakes of $\mathrm{Si}$ are in the range $20-50 \mathrm{mg} / \mathrm{d}$ (Pennington, 1991). However, previous estimates have relied upon food composition data of questionable accuracy and relevance to the populations concerned. The aims of the present study were to investigate dietary intakes of $\mathrm{Si}$, and the contributions of individual food groups to Si intakes amongst healthy post-menopausal UK women using a recently developed food composition database for UK foods (Powell et al. 2005).

\section{Methods}

Subjects were recruited as part of a separate 2-year randomised controlled intervention trial evaluating the effects of vitamin $\mathrm{K}$, vitamin $\mathrm{D}$ and $\mathrm{Ca}$ on bone health in elderly women (BoltonSmith et al. 2001a, 2002). Healthy female subjects over 60 years of age were recruited from the general population in approximately equal numbers in 5-year age groups (6064 years, $65-69$ years, $70-74$ years and $>75$ years). Exclusion criteria included clinical osteoporosis or chronic disease such as diabetes mellitus, CVD and cancer, fat malabsorption 
syndromes, routine medication that interferes with vitamin $\mathrm{K}$, vitamin $\mathrm{D}$ or bone metabolism (notably warfarin and steroids) or routine consumption of dietary supplements that provided in excess of $30 \mu \mathrm{g}$ vitamin $\mathrm{K}, 10 \mu \mathrm{g}$ vitamin $\mathrm{D}$ or $500 \mathrm{mg} \mathrm{Ca}$ daily. Subjects provided informed signed consent in accordance with the Tayside Committee of Medical Research Ethics. For further details of methods and results, see Bolton-Smith et al. (2001b) and Powell \& Bolton-Smith (2003).

Of 244 eligible women randomised into the study, 209 completed the full 2-year intervention with acceptable compliance (Bolton-Smith et al. 2001a). Reasons for withdrawal were illness unrelated to the study ( $n$ 14), volunteer decision ( $n$ 15), clinically low bone mineral density $(n 4)$ and death $(n 2)$.

Baseline assessments of dietary intakes were conducted in the winter season (October to January) and subjects attended clinics every 6 months for reassessment with these time-points reflecting both winter and summer seasons. Dietary intake was assessed over the preceding 3-4 months by a self-administered, semiquantitative food-frequency questionnaire (FFQ) developed by the Scottish Collaborative Group (New \& Bolton-Smith, 1993; New et al. 1997; McNeill, 2005). This FFQ was developed based on an FFQ used in the Scottish Heart Health Study (Bolton-Smith et al. 1991). The FFQ consisted of 150 specific foods or food types grouped into nineteen food groups. For each item on the FFQ, subjects were asked to record how many times per week they consumed the food with response options from 'rarely or never' to '7 days per week' and how many times per day they consumed the food with response options from 'once per day' to 'four times or more per day'. Subjects were asked to recall their frequency of consumption over the preceding 3-4 months.

Food composition data on the Si content of UK foods from recent laboratory analysis were used to determine the Si content of food items on the FFQ (Powell et al. 2005). Standard principles and criteria were employed in the development of the $\mathrm{Si}$ food composition database (Rand et al. 1987, 1991). Standardised recipes (Food Standards Agency, 2002) or manufacturer's ingredient information were used to calculate $\mathrm{Si}$ content where necessary. Values for different forms of the same food or for similar foods were substituted where necessary and, if necessary, adjustments were made for differences in water, protein, sugar or fat content or for weight changes on cooking using standardised procedures (Rand et al. 1987, 1991). For example, values for fresh white bread were used for toasted white bread with adjustments made for the change in water content upon toasting. Si content values for water appropriate for this Scottish population was used in the analysis (Tayside tap water, $0.13 \mathrm{mg} / 100 \mathrm{ml}$ ). Where FFQ items represented a food group, the mean $\mathrm{Si}$ content of representative foods was used. Daily Si intake was calculated by multiplying the daily intake of the FFQ items expressed in $\mathrm{g} / \mathrm{d}$ by the $\mathrm{Si}$ content of the food. Means, standard deviations and median intakes were calculated for the study population and one-way ANOVA was used to compare mean intakes across age groups. The percentage contribution of individual food groups to $\mathrm{Si}$ intake was calculated as the $\mathrm{Si}$ provided by each food group divided by the total $\mathrm{Si}$ intake and converted to a percentage for each person. Means and standard deviations were calculated for the group. All data management and statistical analysis was conducted using the SPSS for Windows, standard version, release 10.0.5 (SPSS, Chicago, IL, USA). $P \leq 0.05$ was considered to be significant.
Table 1. Silicon intakes $(\mathrm{mg} / \mathrm{d})$ in Scottish women aged $>60$ years determined by food-frequency questionnaire over 2 years

(mean values and standard deviations, medians and ranges)

\begin{tabular}{lcccc}
\hline Time & Mean & Median & SD & Range \\
\hline Baseline & $18 \cdot 6$ & $18 \cdot 4$ & $4 \cdot 6$ & $7 \cdot 7-31 \cdot 8$ \\
6 months & $18 \cdot 3$ & $18 \cdot 2$ & $5 \cdot 2$ & $5 \cdot 0-37 \cdot 4$ \\
12 months* & $18 \cdot 3$ & 17.9 & $5 \cdot 1$ & $4 \cdot 0-33 \cdot 4$ \\
18 months $^{*}$ & $18 \cdot 1$ & $18 \cdot 2$ & $4 \cdot 6$ & $4 \cdot 3-32 \cdot 0$ \\
24 months & $18 \cdot 6$ & 18.5 & $5 \cdot 1$ & $5 \cdot 9-34 \cdot 0$ \\
\hline
\end{tabular}

* $n 208$ as one subject at each time-point did not complete a food-frequency questionnaire, otherwise $n 209$.

\section{Results}

A total of 209 women, with a mean age of 68.2 (SD 5.7) years and a mean BMI of 26.1 (SD 3.4$) \mathrm{kg} / \mathrm{m}^{2}$, completed the 2-year intervention study and were included in this analysis. The mean, standard deviation, median and range of Si intakes, in $\mathrm{mg} / \mathrm{d}$, at each visit were calculated from the FFQ (Table 1). There were no significant differences between mean intake at any of the timepoints, assessed using one-way ANOVA. Therefore, all further analysis used intake at baseline only (18.6 (SD 4.6) $\mathrm{mg} / \mathrm{d}$ ). Si intakes across age groups at baseline are presented (Table 2). Again, there were no differences in intake by age group as assessed using one-way ANOVA. Mean energy intake was 1866 (SD 493) $\mathrm{kcal} / \mathrm{d}$ and the mean energy intake:BMR ratio was 1.46 (SD 0.42). Using a cut-off of 1.35 to indicate low-energy reporting (Goldberg et al. 1991), $42 \%$ of subjects were classified as low-energy reporters. Mean Si intakes at baseline when lowenergy reporters were excluded from the analysis were $20 \cdot 8$ (SD 4.0$) \mathrm{mg} / \mathrm{d}$ and mean $\mathrm{Si}$ intakes did not vary according to time-point or age groups.

The greatest contributor to $\mathrm{Si}$ intakes was the cereal group (about $30 \%$ ) followed by fruit, beverages and vegetables, with these foods providing over $75 \%$ of Si intake (Table 3). Hot beverages (tea and coffee) were relatively high sources of Si intake due to their frequency of consumption and the Si content of drinking water used in their preparation $(0.25 \mathrm{mg} \mathrm{Si} / 100 \mathrm{ml})$, rather than a high Si content in the raw product. There was considerable variation (as shown by the standard deviation and range) in the percentage contribution of each of the main food groups to $\mathrm{Si}$ intakes (Table 3), which reflects variation in dietary patterns amongst individuals. Results were similar when low-energy reporters were excluded.

The major contributors to $\mathrm{Si}$ intake were investigated further (Fig. 1). For example, wholemeal bread provided the greatest proportion of Si intake (9.9\% of total intake) among the cereal products (Fig. 1(a)). Of note, and perhaps unique to a Scottish population, was the approximately equal contribution of oatcakes

Table 2. Silicon intakes $(\mathrm{mg} / \mathrm{d})$ as determined by food-frequency questionnaire by 5 -year age groups in Scottish women aged $>60$ years at baseline (mean values and standard deviations, medians and ranges)

\begin{tabular}{|c|c|c|c|c|c|c|}
\hline Age group (years) & $n$ & $\%$ & Mean & Median & SD & Range \\
\hline $60-64$ & 59 & $28.2 \%$ & $18 \cdot 3$ & $18 \cdot 6$ & $5 \cdot 0$ & $7 \cdot 7-31 \cdot 8$ \\
\hline $65-69$ & 72 & $34.4 \%$ & $18 \cdot 8$ & $19 \cdot 0$ & 4.6 & $9 \cdot 3-30 \cdot 2$ \\
\hline $70-74$ & 48 & $23.0 \%$ & $18 \cdot 6$ & $18 \cdot 1$ & 4.2 & $9 \cdot 6-29 \cdot 0$ \\
\hline$>75$ & 30 & $14.4 \%$ & $18 \cdot 6$ & $18 \cdot 0$ & 4.5 & $8 \cdot 5-29 \cdot 0$ \\
\hline
\end{tabular}


Table 3. Contribution (\%) by food groups to silicon intakes among 209 elderly Scottish women aged $>60$ years at baseline

(mean values and standard deviations, medians and ranges)

\begin{tabular}{|c|c|c|c|}
\hline Food group & Mean & SD & Range \\
\hline Cereals (breakfast cereals, breads, rice, pasta) & 29.5 & $9 \cdot 5$ & $3 \cdot 7-50$ \\
\hline All fruit (fresh, tinned and dried)* & $18 \cdot 7$ & 8.5 & $0.5-45.5$ \\
\hline Hot beverages (tea and coffee) & $14 \cdot 9$ & $5 \cdot 8$ & $0 \cdot 0-38 \cdot$ \\
\hline All vegetables (including potatoes) & $11 \cdot 2$ & $5 \cdot 3$ & $2 \cdot 6-52 \cdot \varepsilon$ \\
\hline Biscuits and cakes & 8.9 & $5 \cdot 6$ & $0.0-29.5$ \\
\hline Miscellaneous/other foods $†$ & $3 \cdot 1$ & 1.8 & $0.0-11$. \\
\hline Alcoholic beverages & $2 \cdot 4$ & $3 \cdot 8$ & $0 \cdot 0-24 \cdot \varepsilon$ \\
\hline Beans and legumes & $2 \cdot 3$ & 1.6 & $0.0-8.7$ \\
\hline $\begin{array}{l}\text { All dairy products (milk, milk products } \\
\text { and cheese) }\end{array}$ & $2 \cdot 0$ & 0.7 & $0 \cdot 8-5 \cdot 2$ \\
\hline Meat and meat products & $1 \cdot 6$ & $1 \cdot 7$ & $0 \cdot 0-13$ \\
\hline Puddings and desserts & $1 \cdot 7$ & 1.9 & $0 \cdot 0-12 \cdot($ \\
\hline Fish and fish products & $1 \cdot 1$ & 0.7 & $0.0-3.9$ \\
\hline Confectionery and sweets & $1 \cdot 1$ & $1 \cdot 6$ & $0.0-13 \cdot 6$ \\
\hline Cold beverages & $1 \cdot 0$ & $1 \cdot 0$ & $0.0-7.6$ \\
\hline Fats and oils & 0.7 & 0.6 & $0.0-3.0$ \\
\hline Eggs and egg dishes & 0.1 & 0.1 & $0.0-0.5$ \\
\hline
\end{tabular}

*Bananas contributed the majority of silicon from fruit at 13.3 (SD7.3) \%.

† Miscellaneous/other foods includes soups, nuts, savoury snacks, sauces, sweet spreads and sugar.

to all other biscuits, in terms of $\mathrm{Si}$ intake. This is due to their popularity in the population studied and because they have an especially high Si content. Fig. 1(b) indicates the contribution of specific fruits and vegetables to $\mathrm{Si}$ intakes with bananas contributing the majority of dietary $\mathrm{Si}$ ( $13.3 \%$ of total intake). Finally, of the vegetable group, green vegetables provided the greatest amount of $\mathrm{Si}(6.0 \%$ of total intake).

\section{Discussion}

The aim of the present study was to investigate the dietary intake of Si amongst older healthy women in the UK in a cohort of Scottish women involved in an intervention study in which diet had been assessed by FFQ. We used our recently developed UK food composition database for $\mathrm{Si}$ (Powell et al., 2005) to identify the important food sources of $\mathrm{Si}$ in the Scottish diet.

Mean Si intake of women aged over 60 years was 18.6 (SD 4.6) $\mathrm{mg}$ and did not vary significantly across the 2 years of investigation, indicating little seasonal variation in intake. Moreover, $\mathrm{Si}$ intakes did not differ across age groups of older women. Cereals provided the greatest amount of Si in the diet (about 30\%) which, along with beverages and other plant-based foods, provided over $75 \%$ of $\mathrm{Si}$ intake.

As noted earlier, there have been very few estimates of Si intake in human populations. Based on analysis of a limited number of foods, Bowen \& Peggs (1984) estimated the intake of $\mathrm{Si}$ from British diets to be $30.8 \mathrm{mg} / \mathrm{d}$ with approximately $60 \%$ from cereals, $20 \%$ from water and beverages and $9 \%$ from root vegetables. Close comparisons with our present findings

(a)

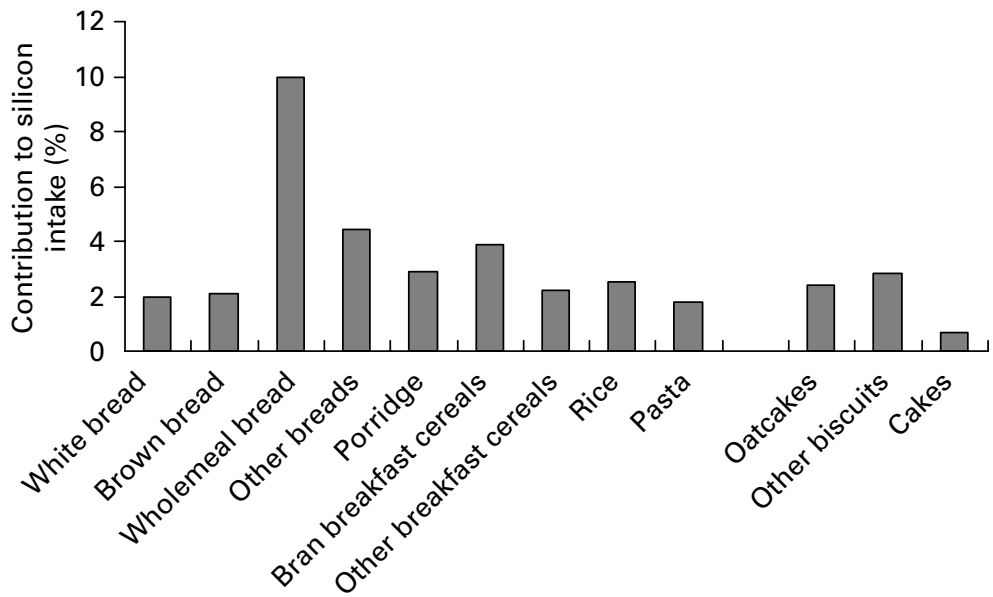

(b)

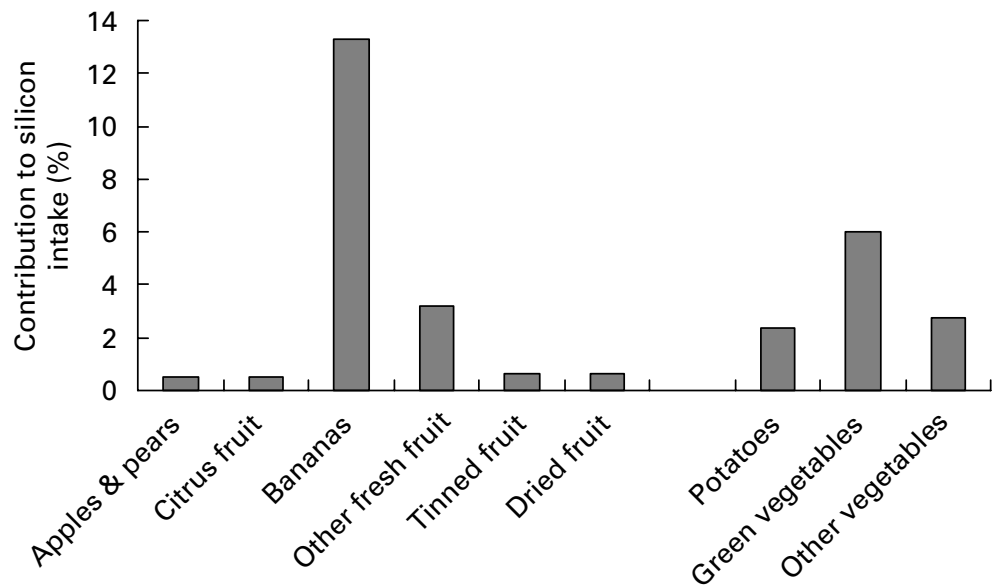

Fig. 1. Percentage contribution of specific foods and food groups to daily silicon intake: (a) cereals, biscuits and cakes; (b) fruits and vegetables 
are difficult as their estimates were based on modelled diets rather than dietary intake assessments, and although they used food $\mathrm{Si}$ values based on analysis of British foods, their data were limited and expressed on the basis of dry weight.

Pennington (1991) provided estimates of intakes for US men and women aged 25-30 years of age based on consumption of 201 foods from the 1983 US Total Diet Study. The intake for men was approximately $40 \mathrm{mg} / \mathrm{d}$ while the intake for women was approximately $19 \mathrm{mg} / \mathrm{d}$. For the women, the most important contributor to $\mathrm{Si}$ intake was beverages (all types) which provided $27.9 \%$, followed by grains and grain products (20.0\%; white bread, 6.4\%), vegetables (14.6\%) and fruit $(8.3 \%)$. Estimates of the Si content of foods were based upon collated published literature values from food analysis, with the majority of data based on the analysis of $\mathrm{Si}$ in non-US foods (Pennington, 1991). The higher Si intake among men was probably due to a higher overall energy intake, and a higher intake of Si-containing beverages, particularly beer (Pennington, 1991), which has an especially high content of dietary Si (Sripanyakorn et al. 2004).

More recently, $\mathrm{Si}$ intakes were estimated in the Framingham Heart Disease Cohorts in the USA (Jugdaohsingh et al. 2002). $\mathrm{Si}$ intakes were estimated for subjects in the Original Cohort and in the Offspring Cohort using a 126-item FFQ, again mostly using the food composition data collated by Pennington (1991). Mean intakes for women were 24 and $25 \mathrm{mg} / \mathrm{d}$ for the Original Cohort (aged 67-93 years) and the Offspring Cohort (aged 26-81 years), respectively. Si intakes decreased significantly with age with intakes $0.1 \mathrm{mg}$ lower for every extra year and $\mathrm{Si}$ intakes were lower among females than males, although results were not adjusted for energy intake. With respect to the contribution from particular foods or food groups, the results are not directly comparable as only the top ten foods rather than summary food groups are presented (Jugdaohsingh et al. 2002). In the Original Cohort, the most important sources of $\mathrm{Si}$ were bread and cereals (cooked oatmeal, cold cereal, dark and white bread, muffins and breads; 22.9\%) and bananas $(13.9 \%)$

The intakes reported in the current study are marginally lower than those reported by Jugdaohsingh et al. (2002). This probably reflects different eating patterns and differences in food $\mathrm{Si}$ contents between the USA and Scotland, as well as the quality of the food content data. However, comparison of the percentage contributions of food items to $\mathrm{Si}$ intakes showed some similarities, for example, with respect to bananas (13.9 (USA) $v$. $13.3 \%$ (Scotland)), beans and legumes (3.0 v. $2.3 \%)$ and breads $(12.3$ v. $18.4 \%)$. Differences were apparent though, with respect to the percentage contribution from hot beverages. In the UK, coffee provided $8.4 \% \mathrm{Si}$ intake and tea provided $6.5 \%$, while in the USA coffee provided only $3 \% \mathrm{Si}$ intake and although the contribution of tea was not reported in the published paper, it is likely to be substantially lower than in the UK (Jugdaohsingh et al. 2002).

One of the major strengths of the current study is the use of relevant food composition data in assessing the dietary intakes of the study population. Both the study by Pennington (1991) and Jugdaohsingh et al. (2002) used food composition data based on published literature values with a large volume of data based on the analysis of Finnish foods and old estimates with uncertainties surrounding appropriate analytical methodologies and unclear relevance to their study populations. The food composition data used in the current study is of a high quality, representing the range of foods available to British populations and, in addition, the content of Si in local drinking water has been taken into account (Powell et al., 2005). Moreover, analyses were undertaken from five consecutive dietary assessments over a 2-year period which yielded consistent findings.

Bioavailability of Si may depend largely on the chemical form of Si (Nielsen, 1999; Van Dyck et al. 1999). Orthosilicic acid, present in drinking water and other fluids, is considered to be the predominantly bioavailable form of $\mathrm{Si}$ while plant foods provide predominantly phytolithic silica which had once been considered largely insoluble and not available for absorption in the gastrointestinal tract (Reffitt et al. 1999). However, recent studies have shown that $\mathrm{Si}$ from plant foods is almost as bioavailable as that from drinking water and other fluids, perhaps due to hydrolysis of phytolithic silica in the gastrointestinal lumen (Jugdaohsingh et al. 2002).

Additionally, the food matrix may also be an important determinant of Si bioavailabilty. For example, $\mathrm{Si}$ from grains and grain products has been shown to be readily absorbed, while the $\mathrm{Si}$ in certain fruits was less readily absorbed; for example, despite their high $\mathrm{Si}$ content, bananas provide poorly absorbed $\mathrm{Si}$ (Jugdaohsingh et al. 2002). However, from an epidemiological perspective, significant correlations have been observed between estimated $\mathrm{Si}$ intake and $\mathrm{Si}$ absorption, which suggests that the intakes estimated from the $\mathrm{Si}$ content of foods can be used to estimate dietary Si exposure (Jugdaohsingh et al. 2002).

Minimum daily requirements for $\mathrm{Si}$ have not been established but are estimated at $10-25 \mathrm{mg} / \mathrm{d}$ based upon the $24 \mathrm{~h}$ urine collections (Carlisle, 1997). The lower end of this range is consistent with our previous data from which we estimated mean daily absorption of Si to be $10-13.5 \mathrm{mg} / \mathrm{d}$ for men and women (Jugdaohsingh et al. 2002). More recently, Si intakes greater than $30 \mathrm{mg} / \mathrm{d}$ were associated with significantly increased bone mineral density when compared to intakes of less than $18 \mathrm{mg} / \mathrm{d}$ in pre-menopausal women and men (Jugdaohsingh et al. 2004). Use of the new Si food composition database will allow further such studies to be undertaken in the UK, confirming the purported associations between dietary $\mathrm{Si}$ and human health and providing some insights into optimal $\mathrm{Si}$ intakes.

\section{Conclusions}

Mean Si intake in Scottish females aged over 60 years did not vary significantly over time or by age. Intakes were marginally lower than reported in a previous study of women in the USA and there were minor differences in the food sources of $\mathrm{Si}$. Characterisation of the $\mathrm{Si}$ intakes in this population using a recently developed food composition database based on analysis of relevant foods will allow further investigation of the role of $\mathrm{Si}$ in human health.

\section{Acknowledgements}

The Food Standards Agency funded the original collection of dietary data (NO5001) and the $\mathrm{Si}$ food composition analysis and secondary dietary data analysis (NO5034). R. J. is supported by a fellowship from The Frances and Augustus Newman Foundation. 


\section{References}

Bolton-Smith C, Casey CE, Gey KF, Smith WCS \& Tunstall-Pedoe H (1991) Antioxidant vitamin intakes assessed using a food-frequency questionnaire: correlation with biochemical status in smokers and non-smokers. Br J Nutr 65, 337-346.

Bolton-Smith C, Mishra GD, Mole PA, McMurdo MET \& Paterson CR (2001a) A longitudinal study of the relationship between serum 25$\mathrm{OH}$ vitamin $\mathrm{D}$ and parathyroid hormone $(\mathrm{PTH})$ concentrations in older women (abstract). Proc Nutr Soc 60, 159A.

Bolton-Smith C, Mole PA, McMurdo MET, Shearer MI \& Paterson CR (2002) Effect on bone mineral content of supplements of vitamin K, vitamin D and calcium in older women (abstract). J Bone Miner Res 17, 1335.

Bolton-Smith C, Shearer MJ, McMurdo MET \& Paterson CR (2001b) Evaluation of the Effects of a 2-year Intervention with Calcium and Vitamins D and K on Bone Health in Elderly Women. Final Report to the Food Standards Agency (Project N05001). London: Food Standards Agency.

Bowen HJM \& Peggs A (1984) Determination of the silicon content of food. J Sci Food Agric 35, 1225-1229.

Carlisle EM (1981) Silicon: a requirement in bone formation independent of vitamin D. Calc Tissue Int 33, 27-34.

Carlisle EM (1997) Silicon. In Handbook of Nutritionally Essential Mineral Elements, pp. 6.3-6.8 [BL O'Dell and RA Sunde, editors]. New York: Marcel Dekker.

Expert Group on Vitamins and Minerals (2003) Safe Upper Levels for Vitamins and Minerals. London: Food Standards Agency.

Food Standards Agency (2002) McCance and Widdowson's The Composition of Foods, 6th summary ed.Cambridge: Royal Society of Chemistry.

Goldberg GR, Black AE, Jebb SA, Cole TJ, Murgatroyd PR, Coward WA \& Prentice AM (1991) Critical evaluation of energy intake data using fundamental principles of energy physiology: 1. Derivation of cut-off limits to identify under-recording. Eur J Clin Nutr 45, 569-581.

Jugdaohsingh R, Anderson SHC, Tucker KL, Elliott H, Kiel DP, Thompson RPH \& Powell JJ (2002) Dietary silicon intake and absorption. Am J Clin Nutr 75, 887-893.

Jugdaohsingh R, Reffitt DM, Oldham C, Day JP, Fifield LK, Thompson RPH \& Powell J (2000) Oligomeric but not monomeric silica prevents aluminium absorption in humans. Am J Clin Nutr 71, 944-949.

Jugdaohsingh R, Tucker KL, Qiao N, Cupples LA, Kiel DP \& Powell JJ (2004) Dietary silicon intake is positively associated with bone mineral density in men and premenopausal women of the Framingham Offspring Cohort. J Bone Miner Res 13, 297-307.

McNeill G (2005). Scottish Collaborative Group food frequency questionnaire. Department of Environmental \& Occupational Medicine, University of Aberdeen. http://www.foodfrequency.org/

New SA \& Bolton-Smith C (1993) Development of a food frequency questionnaire. Proc Nutr Soc 52, 330A.
New SA, Bolton-Smith C, Grubb DA \& Reid DM (1997) Nutritional influences on bone mineral density: a cross-sectional study in premenopausal women. Am J Clin Nutr 65, 1831-1839.

Nielsen FH (1999) Ultra-trace minerals. In Modern Nutrition in Health, pp. 283-327 [ME Shils, JA Olson, M Shike and AC Ross, editors]. Philadelphia: Lippincott Williams \& Wilkins.

Parry R, Plowman D, Delves HT, Roberts NB, Birchall JD, Bellia JP, Devenport A, Ahmad R, Fahal I \& Altman P (1998) Silicon and aluminium interactions in haemodialysis patients. Nephrol Dial Transplant 13, 1759-1762

Pennington JAT (1991) Silicon in food and diets. Food Addit Contam 8 , 97-118.

Perez-Granados AM \& Vaquero MP (2002) Silicon, aluminium, arsenic and lithium: Essentiality and human health implications. J Nutr Health Aging 6, 154-162.

Powell JJ \& Bolton-Smith C (2003) Interaction Between Silicon Intake and Vitamin $D$ and $K$ Status on Markers of Bone Health in Older Women. Final Report to the Food Standards Agency (Project N05034). London: Food Standards Agency.

Powell JJ, McNaughton SA, Jugdaohsingh R et al. (2005) A provisional database for the silicon content of foods in the United Kingdom. Br J Nutr 94, 804-812.

Rand WM, Pennington JAT, Murphy SP \& Klensin JC (1991) Compiling Data for Food Composition Data Bases. Tokyo: United Nations University Press.

Rand WM, Windham CT, Wyse BW \& Young VR (1987) Food Composition Data: A User's Perspective. Tokyo United Nations University Press.

Reffitt DM, Jugdaohsingh R, Thompson RPH \& Powell JJ (1999) Silicic acid: its gastrointestinal uptake and urinary excretion in man and effects on aluminium excretion. J Inorg Biochem 76, 141-147.

Reffitt DM, Ogston N, Jugdaohsingh R, Cheung HJF, Evans BAJ, Thompson RPH, Powell JJ \& Hampson GN (2003) Orthosilicic acid stimulates collagen type 1 synthesis and osteoblastic differentiation in human osteoblast-like cells in vitro. Bone $\mathbf{3 2}$, $127-135$.

Schwarz K (1977) Silicon, fibre and atherosclerosis. Lancet i, 454-457.

Schwarz K, Ricci BA, Punsar S \& Karvonen MJ (1977) Inverse relation of silicon in drinking water and atherosclerosis in Finland. Lancet $\mathbf{i}$ $538-539$.

Sripanyakorn S, Jugdaohsingh R, Elliott H, Walker C, Mehta P, Shouker S, Thompson RPH \& Powell JJ (2004) The silicon content of beer and its bioavailability in healthy volunteers. $\mathrm{Br} J \mathrm{Nutr} \mathbf{9 1}$, 403-409.

Van Dyck K, Van Cauwenbergh R, Robberecht H \& Deelstra H (1999) Bioavailability of silicon from food and food supplements. Fresenius J Anal Chem 363, 541-544. 